\title{
Supply chain capability creation - The creation of the supply chain readiness for a new product during product development process
}

\author{
Arto Tolonen, Harri Haapasalo, Janne Harkonen, Jordan Verrollot
}

\begin{abstract}
The ever-increasing importance of creating and developing solutions and products that not only secure customer satisfaction but also enable cost efficient supply chain process are topical issues today. Therefore, the main purpose of this study is to widen the scope of traditional new product development (NPD) process to cover the expected activities from supply chain (SC) process viewpoint. Supply chain capability creation (SCCC) process can be seen as the sub-process of the NPD process that extends the NPD process governance models, targets, key performance indicators, tasks, milestone criteria and roles. The main target of the SCCC process is to influence the product design itself and on the other hand to enable smooth and cost efficient product ramp up according to the SC strategy and supply chain models. The economics of the production and SC can be greatly impacted by the systematic preparation of the SC for the new product during the NPD process according to well-documented and implemented SCCC process.

Earlier NPD related research covers well the hardware and software development but the overall SC activities have not been studied systematically as a separate sub-process. In our research, we first review the literature and then analyse a case company that represents hardware, software, services and solutions type businesses.

The main contribution of this study is introducing a new SCCC sub-process as a part of NPD process. The SCCC process lowers the new product related supply chain costs due to better design of new products and systematic preparation of the SC to ramp up the new product. Nevertheless, the role of SCCC process as a means for strategic SC activities in NPD life-cycle phase sets further questions for researchers' for systematic SCCC activities even prior the NPD phase, during technology development.
\end{abstract}

Keywords: Supply Chain Process, New Product Development Process, Supply Chain Capability Creation Process, Supply Chain Capability Manager, Supply Chain Management

\section{Introduction}

New product development (NPD) process is considered as a strategic activity, while the related metrics, short time-to-market, total cost and product performance are all as important to companies' long-term success. The current research in NPD has mostly focused on those issues in isolation with the supply chain (SC) process (Gerwin and Barrowman, 2002). Research that simultaneously focuses on the coordination of both NPD and SC for bringing new products to the market is scarce (Carrillo and Franza, 2006; Van Hoek and Chapman, 2007; Hilletofth et al., 2010; Marsillac and Roh, 2014). Nevertheless, strategic alignment is pointed out as the most important success factor for the development of business processes and performance management practices (Bai and Sarkis 2013). As an example of strategic alignment, a manufacturing strategy creation should involve stakeholders from NPD and SC organisations, including production system requirements (Adamines and Pomonis, 2006). According to Pinheiro de Lima et al. (2013) company's business processes and their performance management should be connected together as an integrated performance management framework. In fact, during the dot.com boom, extensive renovation and reinvention of business models took place (Suikki et al. 2006). At the same time, sales items that companies were developing, selling and delivering have also been renewed (Pekuri et al. 2013; Sahlman and Haapasalo 2011). Then not only the rate of product renewals, but also business model renewals, and eventually SC process renewals took place more often increasing also the importance of preparing the supply chain readiness during the NPD process. Paying particular attention to the supply chain readiness during the NPD process can be valuable for companies in today's business due to the nature of product development.

The share of totally new product development is decreasing which is seen as a drop of business performance (Barczak et al., 2009) and can be seen as a motivation to look at NPD practices and 
potential performance improvement outside of pure product innovations. The lack of research addressing these issues is surprising since short time-to-market, total cost and product performance are affected by various SC activities. Carrillo and Franza (2006) argue that NPD process must assist in the ramp up of the SC processes and other activities that support the commercialisation of the newly developed product. Instead of cleaning up after the NPD, the SC process representatives should be involved from the beginning of product development process (Van Hoek and Chapman, 2007). Specifically, the previous research does not address how to build and prepare the operational supply chain readiness (supply chain capability) along with the NPD phases and milestones.

The operational SC process can be seen to consists of sub-processes and activities including demand and supply planning, purchasing, production, order management, distribution and invoicing. The supply chain capability (SCC) can be seen as the performance of the operational SC process to execute its planned activities according to agreed performance targets and metrics (Lummus and Vokurka, 1999; Swafford et al., 2006). Indeed, the SCC should not be mixed with the supply chain capability creation (SCCC). According to the empirical analysis of this study, the SCCC process can be seen to create the SCC for a new product during the NPD process. SCCC process has been created and documented as a sub-process of the NPD. The SCCC process related managerial role and responsibility is adopted by the Supply Chain Capability Manager (SCCM).

This study aims at exploring the SCCC process, which can be seen as the linkage between NPD process and SC process including managerial responsibilities. The major part of the study involves current state analysis of a single case company practices focusing on the NPD process, in more detail on the concept of SCCC process to analyse systematic creation of supply chain readiness for a new product during the NPD process.

The above discussion can be condensed into the following research questions:

- RQ1. What are the generic requirements for supply chain capability creation?

- RQ2. How is the supply chain capability creation organised in the case company?

- RQ3: What are the preconditions for systematic supply chain capability creation?

This study addresses the research questions by using a qualitative and inductive approach, through case company interviews and a literature review. RQ1 is answered in chapter 2 by reviewing the literature and the earlier research on supply chain capability creation. RQ2 is answered in chapter 3 as a result of the empirical single case study. RQ3 is answered in chapter 4 by utilising the results of RQ1 and RQ2 by developing and validating the proposed preconditions for supply chain capability creation.

\section{Literature review}

NPD is the process of moving new products from idea generation into a market introduction, including product design, market study and marketing analyses (Cooper, 2001; Ulrich and Eppinger, 2008; Liker 2004). NPD is a process comprising of sequential steps, or set of activities beginning with the perception of a market opportunity and ending in the sales, production and delivery of a product (Ulrich and Eppinger, 2008). Typical phases (P) for NPD process are P0 feasibility study, P1 project planning, P2 concepting, P3 development and integration, P4 piloting and P5 ramp-up (Cooper, 2001). Since the 90s, a number of NPD frameworks (Cooper, 2001; Ulrich and Eppinger, 2008) have emerged to meet the various needs of organisations. Most of these frameworks possess a number of similar important characteristics which, when executed in a balanced and effective manner, can significantly improve NPD performance (Ahmed, 2002): 
- The use of a structured development process, describing entry and exit criteria between key project/program milestones, the primary task, the schedule and the resource assignments.

- A team of senior executives (review board) who provide the oversight of the projects and programs by resolving cross-project issues, setting projects' priorities and make Go/Kill decisions.

- Use of realisation teams, cross-functional execution teams

- Stage/gate reviews at major development milestones, when funding, resources and project schedules are approved or rejected, or postponed by the review board.

The supply chain management (SCM) has a critical role in the companies' strategic decision-making process due to dynamic changes and opportunities in the global supply chain network ( $\mathrm{Su}$ and Gargeya, 2012). Therefore a well-documented NPD and SCCC processes for new product development is vital already at the very early phase of NPD in order to have the investments and related decisions done in a timely manner, and to avoid the possible ramp-up delays due to late activities (Carrillo and Franza, 2006; Khan et al., 2012; Tracey et al., 2005). The main targets of the new product ramp-ups are related to mature supply chain capability at the targeted cost level, capacity, time, and quality (Hüntelmann et al., 2007; Elstner and Krause, 2014; Pufall et al., 2007; Surbier, 2014; Stauder et al., 2014). According to Hsu et al. (2009), operations capability includes firms' new product design and development, just in time, and total quality management capabilities. The SCC can be seen as an element of supply chain strategy and a competitive advantage (Morash, 2000). According to Lynch et al. (2000), the SCC consists of two viewpoints as the capability to supply, manufacture and deliver the products efficiently, and to meet customer demand even for tailored products and services. The impact of the collaboration for the supply chain value has a positive influence on the company's performance (Liao and Kuo, 2014). High maturity levels in supply chain capability can be ruined by many individual factors such as lack of right information in a customer order, machinery breakdowns and transportation delays (Fawcett et al., 1997a). The required time for the ramp-up phase critically affects the financial success of the company (Haller et al., 2003). The investments in new technologies, the cost of product development and the shortening product lifecycles increase the number of new product ramp-ups thus the criticality of the successful ramp-up is an increasingly important managerial topic (Terwiesch and Bohn 2001; Cooper, 2001; Almgren, 1999; Pufall et al., 2007; Schmitt and Schmitt, 2013). The variety of the products influences to the SC cost and efficiency (Um et al., 2017). The complexity in the structures of the product, production and supply chain network (von Cube \& Schmitt 2014) set special challenges for the ramp-up phase but can partially be avoided by the early involvement in the NPD process such as supply chain capability creation activities (Gross and Renner, 2010; Elstner and Krause, 2014; Surbier et al., 2014; Ball et al., 2011; Almgren, 2000). New supply chain innovations, reduction of complexity, and cost benefits provided by the suppliers, such as $3^{\text {rd }}$ party logistics service providers, require long-term strategic and operational level relationships, cooperation and commitment (Azzi et al., 2010).

The aim of the SCCC is to ensure smooth and efficient product ramp-ups based on lowest possible cost and time-to-market according to process maturity (Hüntelmann et al., 2007; Carrillo and Franza, 2006). The SCCC can be seen to consist of sub-capabilities as purchasing, production and logistics capabilities. Successful purchasing capability creation during the NPD phase enables efficient product ramp-ups and volume phase production through mature procurement and supply management processes (Berg 2007; Pufall et al., 2012; Almgren, 1999). The most typical challenge for production ramp-up is the lack of right materials and buy-items from the suppliers due to the competence gaps and un-mature processes (Almgren, 1999; Pufall et al., 2012; Berg, 2007). The early involvement and integration of the key suppliers into the product development process and a project team enables potentially lower cost and better design of the product (Petersen et al., 2005). 
Early production capability creation within the NPD process for new products can be the competitive advantage shortening time-to-market lead-time, enabling to launch the product before competitors (Mukerji et al., 2010). The ramp-up is about the start of the sales, supply, production and deliveries for a new product or the start of the production and deliveries for the existing products in a new location (Terwiesch and Bohn 2001). In both cases, the start of the production might require changes in product design (Gross and Renner, 2010). The ramp-up time can even be $25 \%$ of the total volume phase life-cycle (Haller et al., 2003). At the ramp-up phase, several company functions, including external stakeholders, need to work closely together operationally, often for the first time (Schmitt and Schmitt, 2013). From the production viewpoint, the ramp-up can consist of two phases, the preproduction and volume production (Almgren, 2000). The pre-production takes place in the real commercial and industrial environment in order to qualify the maturity of operational processes before the start of volume production. A typical challenge in production ramp-up phase is the already high demand for the new product that has the limited delivery capacity (Terwiesch and Bohn, 2001). In some companies, ramp-ups seem to be operated as projects on their own to enable full supply chain capability once products being sold (Kontio and Haapasalo 2005). It is evident that these project or process models enable more efficient initiation of production. Mature production capability enables higher production volumes earlier and possible changes in production can be done faster (Miltenburg, 2005; Pufall et al., 2007). Critical factors are mature production technology and processes in addition to production quality, flexibility, lead-time and capacity itself (Groover, 2010; Stauder et al., 2014; Ward, 1996; Mukerji et al., 2010). The production capability is impacted also by a product structure and the need for product-specific production processes and technologies (Pufall et al., 2007). Production flexibility enables the production of several different products by the same production lines with minor product specific setups (Mukerji et al., 2010; Ward et al., 1996).

Logistics capability is the management of the material and information flows to have right goods at a right place at a right time (Pufall et al., 2007). The early logistics capability creation within the NPD process enables the mature logistics capability at product ramp-up phase and at the start of volume deliveries (Fawcett et al., 1997b). According to Liu et al. (2013), the logistics capability is an emerging focus area in global operations within the integrated business processes and in complex supply chain networks. The global market environment requires a low-cost global supply chain network, which increases the criticality of well-functioning logistics processes (Fawcett et al., 1997b). According to Azzini et al. (2010), the complexity of the supply chain network and the related information can be reduced by strategic $3^{\text {rd }}$ party logistics providers. Typical challenges at product ramp-up phase are related to lack of correct materials or information due to differences between piloting phase and volume phase supply chain processes (Pufall et al., 2007). The simple product structure and modularity can decrease the complexity of the supply chain network and logistic processes (Pufall et al., 2007; Fawcett et al., 1997b). In addition, the design of the product packages influences the efficiency and the cost of the logistics processes, involving considerations of weight, dimensions, handling devices, mode of transport and recycling (Azzi et al., 2012). High quality and usable logistical information affects the design of the supply chain network within the NPD process and is critical for operational volume phase deliveries and related decision making over the supply chain network (Fawcett et al., 1997b; Shang and Marlow, 2005).

One success factor of NPD is that several business processes can be incorporated in the NPD process, including purchasing, production and logistics (Barczak et al., 2009; Cooper et al., 2004; Kärkkäinen et al., 2001; Schmidt et al., 2009). The supply chain stakeholders can provide feedback during the different product development stages and supply chain design, and NPD can be handled in parallel (Hilletofth et al, 2010; Chen et al, 2005; Carrillo and Franza, 2006). The major steps in new product technologies may also require the development and implementation of new production technologies 
requiring cross-functional collaboration between the NPD and SC organisations (Marsillac and Roh, 2014). NPD not only facilitates the flow of the new products but also assists the ramp-up of the supply chain activities, which then implies to involve the supply chain representatives early in the NPD process (Hilletofth et al, 2010). Previous research highlights the benefits of involving the SC stakeholders during the NPD but does not explain how to SC readiness for delivering the product can be built alongside the NPD process.

All new products with intent to sell require the supply chain readiness from the first prototypes deliveries to the product ramp-ups and volume deliveries. The current literature on NPD covers well the product development activities from the hardware (HW) and software (SW) product development point of view according to stage gate NPD process. The generic requirements for supply chain capability creation at the NPD phase involve the early cross-functional co-operation by internal and external organisations within requirements management, specification and product development phases between product development and supply chain management functions and processes. Systematic creation of the supply chain capability during NPD aims to mature purchasing, production and logistics capabilities at product ramp-up phase. Well-managed supply chain capability creation call for clearly structured and described NPD process and assigned resources. However, the supply chain capability creation, the sub-process of the NPD, has been not studied and described as systematically by the earlier literature.

\section{Research Process and case company analysis}

In order to analyse the current supply chain capability creation activities, five potential case companies were contacted. Only one of the contacted case companies has systematic supply chain capability creation activities described, managed and implemented as a separate sub-process of NPD thus single case study was selected as an empirical research scope. The selected case company is an experienced global innovator with a large product portfolio of mature products consisting of solutions and individual HW, SW and Service products. In addition, the case company is renewing the product portfolio via strong R\&D efforts during ongoing and already completed merger and acquisition cases. The customer base of the case company is global by nature but some regional and customer specific requirements such as product variants are needed to fulfil certain regional, legal and customer requirements.

The research process is shown in Figure 1. This research utilises qualitative research method and inductive logic.

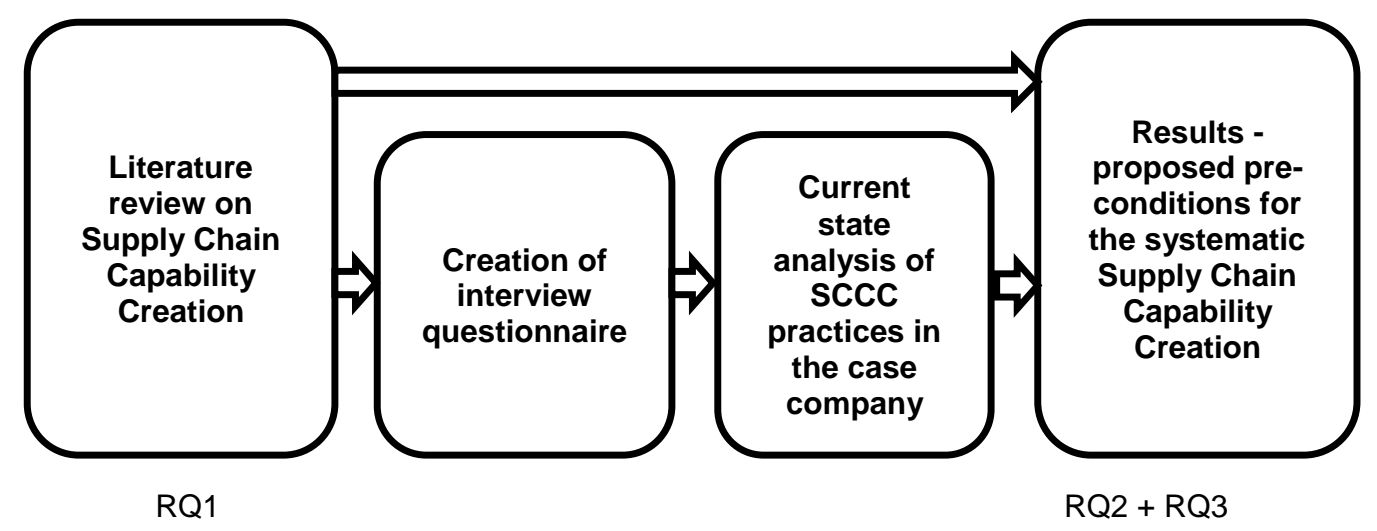

Figure 1. The research steps and process. 
The empirical analysis followed Cooper's concept for NPD state gate process model consisting of product development phases P0, P1, P2, P3, P4 and P5. In addition, related gates were utilised to study the current supply chain capability creation practices in the case company. The empirical study consists of 24 in-depth industrial semi-structured interviews within the case company to clarify the current practices related to SCCC process. The interviewed persons were a global SCCC process owner and three sub-process owners for purchasing, production and logistics capability creation. In addition, 20 supply chain capability managers (SCCMs) were interviewed in order to obtain an understanding of the SCCC process implementation in practice. All interviewed persons have worked over ten years in SCCC process related roles. In addition to analysing the SCCC process, also milestone checklists, process role descriptions and the related training material were analysed to obtain a deep understanding of the case company's current supply chain capability creation practices.

The qualitative approach enabled understanding the studied phenomena via clarifying the meaning and the significance of the phenomena. The qualitative approach allows samples that are discretionary to the researcher. Objects under study may not be high in numbers but are studied thoroughly, highlighting the quality of input material. Nevertheless, the size of sample must be covering enough in relation to the type of analysis and interpretation intended (Marshall and Rossmann, 1998; Siggelkow, 2007; Patton, 2002).

The data sources for this study included semi-structured interviews, personal observations, company confidential material such as NPD and SCCC process descriptions, SCCC project plans and SCCC training material. In addition, internet-based information was utilised. The variety of analysed material enabled triangulating and cross verifying the findings and insights (Yin, 2003). Triangulation helped to ensure the research reliability (McCutcheon and Meredith, 1993).

The same research protocol was utilised in all the interviews yet the emphasis of each interview session was somewhat influenced by the interviewed person and their perspective. The logic and contents of the interviews were reviewed both before and after each interview session to establish a chain of evidence. The reliability of the study is addressed using a research protocol and the development of a case study database (Yin, 2003). Using versatile data sources and maintaining a clear chain of evidence helps this study to establish construct validity.

The study design is based on the principles of design for in-depth case studies (Yin, 2014), involving an in-depth analysis and study of a single focal firm aimed at gathering maximum first-hand information about the studied phenomenon at the company, including Supply Chain Capability Creation, Supply Chain Capability Management, New Product Development and Supply Chain activities. This entails choosing a relevant target company, obtaining highest-level knowledge in the company to provide deep insights into the company activities and conducting semi-structured interviews and in-depth analysis of the relevant company activities.

The case company selection involves the considerations of the case company being a successful example on the studied topic, access to the management team of the company, access to relevant actors for interviews and data collection, and availability of data in the form of company process descriptions, and other company confidential data.

\section{Results and Analysis}

The supply chain capability creation as a systematic sub-process of NPD including related governance models, targets, performance indicators, roles, tasks and milestone criteria has not been presented in the earlier literature adequately thus the empirical research was executed. 


\subsection{Supply Chain process as an enabler for SCCC}

According to interviews and given SCCC documentation, the case company has systematic process descriptions for their business processes such as NPD process, sales process, supply chain process and service process. Each business process and related sub-processes are owned and developed by the nominated process owners. The process owners define the business processes and related subprocesses, document them as process descriptions and educate the operational line organisations to operate accordingly. The managers of the operational line organisations act as process managers to manage their operational activities according to global business process descriptions.

The enabler and the base for the SCCC process are the well-described and implemented operational supply chain process itself. The case company's supply chain process has few "standard" supply chain models that are the only allowed supply chain models for any new products. The case company's supply chain process consists of two main sub-processes: plan for capacity and executes to order (Figure 2). Plan for capacity sub-process includes sub-processes as demand planning, supply planning and demand-supply balancing. The other main level sub-process, execute to order, consists of the sub-processes of inbound, in-house and outbound logistics, production (manufacturing and testing), order management, and invoicing. The plan for capacity process collects the demand information for all products, plans the supply capacity accordingly and balances the demand and supply in case of capacity limitations. The execute to order process manages the operational purchasing, production and logistics activities for the customer orders, deliveries and invoices.

1) Plan for Capacity sub process

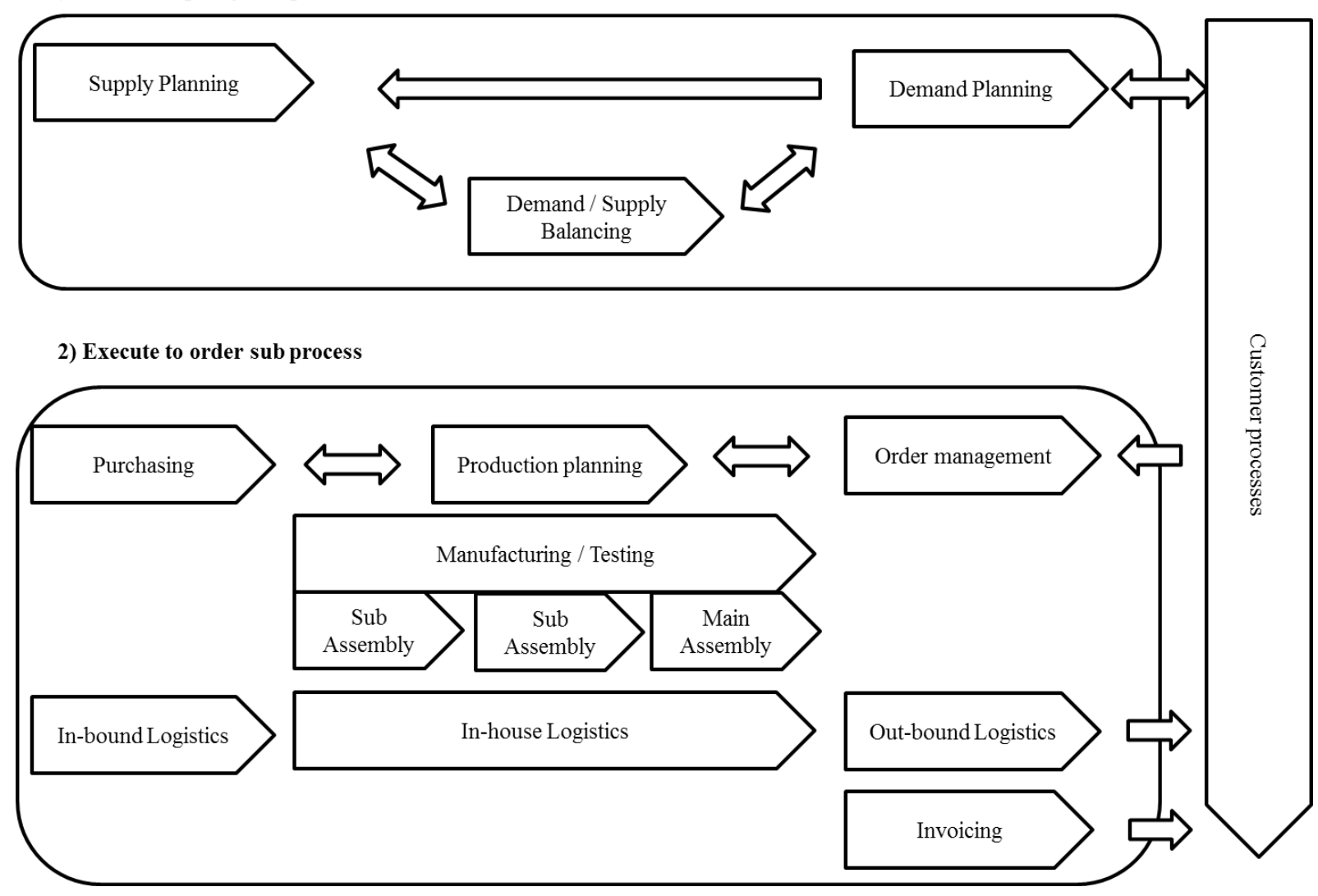

Figure 2. The structure of the supply chain process in the case company 
The supply chain process and its sub-processes form the process platforms, which are developed and owned globally by the global supply chain process owners. The aim of the standardised supply chain process is to ensure the efficiency and flexibility of global operations in production, purchasing and logistics to produce any products anywhere depending on changing business situations and renewal of the customer base and product portfolio. The idea of the supply chain process platforms is to standardise the way of activities as far as possible in global operations function and for their stakeholders such as suppliers and logistics service providers. The supply chain process and its subprocesses are analysed and developed by the process owners according to defined performance targets and metrics. The process managers perform the supply chain process related operational activities according to supply chain process descriptions, targets and metrics. These process managers are operational managers in operations function such as logistics managers, purchasing managers and production managers.

\subsection{SCCC as a sub-process of the NPD process}

The case company has a milestone-driven stage-gate NPD process as the guidance for all new product development locations and NPD projects. The NPD process consists of sub-processes such as HW development, SW development, integration and verification of HW and SW including sub-processes for marketing and sales capability creation, supply chain capability creation and service capability creation. The case company's SCCC process is the sub-process of their NPD process. The case company's NPD process includes not only six but ten milestones. However, for the easier linkage to existing NPD literature, the analysed SCCC activities and gates of the case company are presented in six phases according to Cooper's stage gate model.

In order to utilise the global supply chain process platforms each new product need to be designed accordingly. The product design itself will determine the major part of the related supply chain process costs over the product life-cycle. SCCC process defines the product design guidelines and related targets and key performance indicators. In addition, SCCC process defines the activities and milestone criteria to prepare the supply chain process and operations function for new product rampups. At the early product development phases, the main focus of the SCCC is on the product design while at later phases the SCCC activities focus to supply chain capability creation itself (Figure 3). 


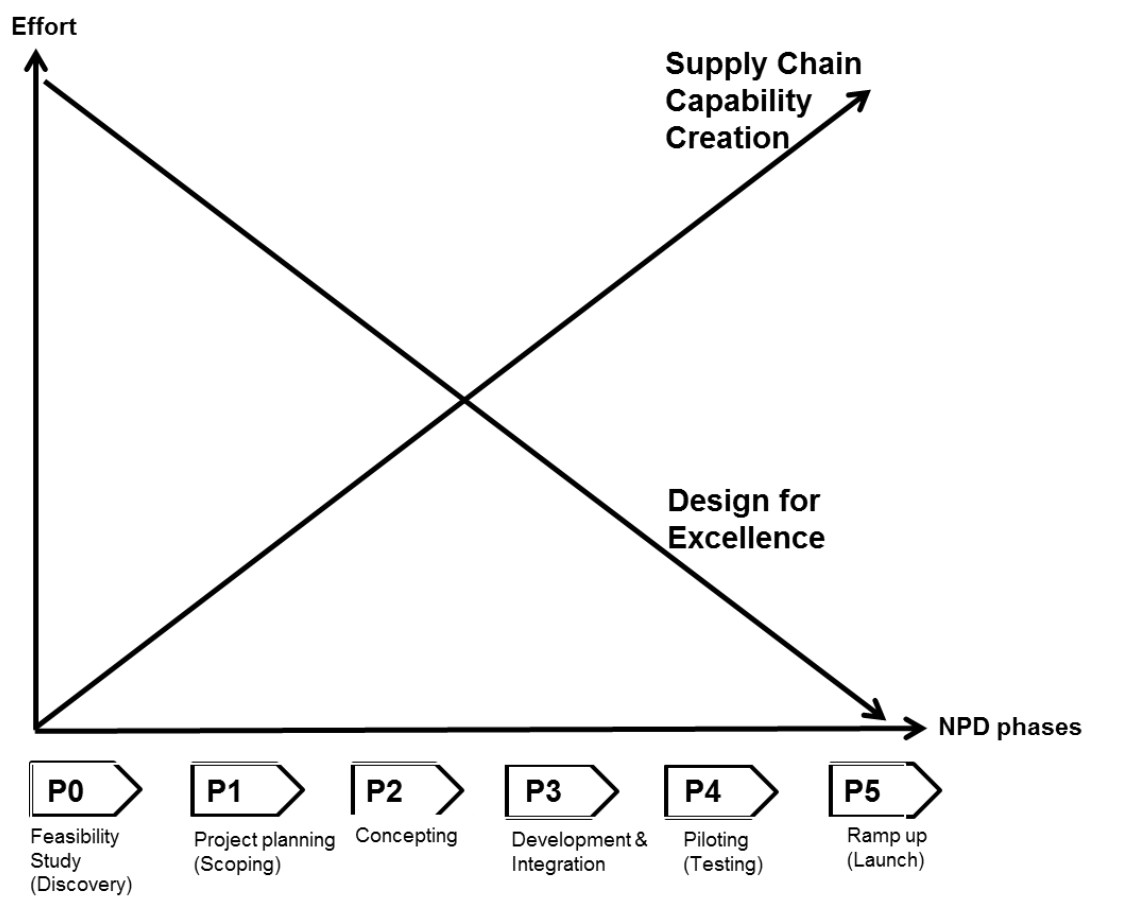

Figure 3. SCCC focus areas.

At the product feasibility study and product concept phases, the SCCC process focuses on the design for excellence (DfX) product design guidelines, targets, key performance indicators and related activities and responsibilities. The DfX concept aims for better product design and fits for the supply chain process. The DfX product design guidelines can be simplified as "what kind of products are good for the supply chain processes". The DfX product design guidelines are based on the product design requirements from the "standard" supply chain process viewpoint that influences product configurability, modularity, manufacturability, testability, logistics and other supply chain process related product design requirements. In addition, a separate product package design platform has been established to design modular unit and transportation packages for all products. The DfX concept is not studied further in this paper to keep the focus on SCCC process.

At the later NPD phases, the SCCC process activities focus on preparing the receiving operations organisation and supply chain process to manage the new product deliveries from first prototypes to zero series and final product ramp-up at the level of agreed delivery volumes. SCCC process consists of generic SCCC project management activities and more specifically purchasing, production and logistics capability creation sub-processes (Figure 4). The completeness of the each phase is checked by the milestone (M) checklists. 


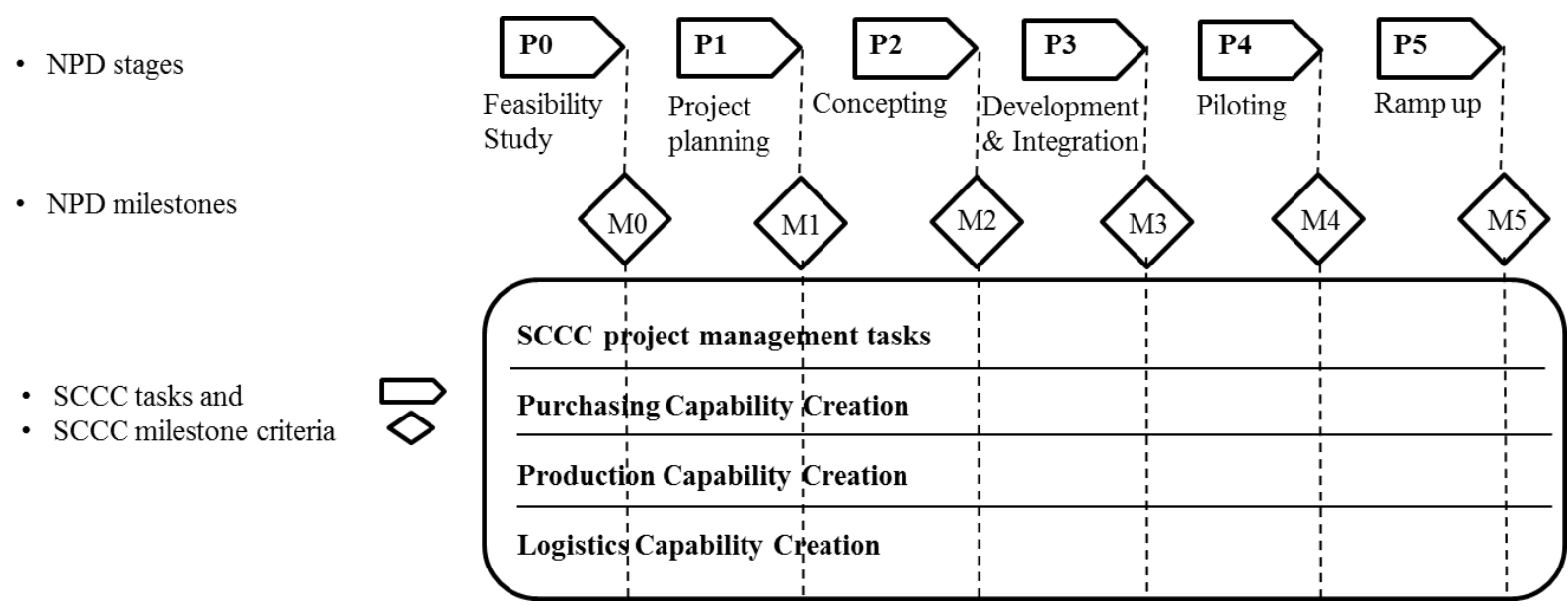

Figure 4. The structure of the SCCC process in the case company

\subsection{SCCC project governance and team set up}

According to interviews, the SCCC process is owned by the nominated global SCCC project owner and three SCCC sub-process owners for purchasing, production and logistics capability creation subprocesses. The supply chain capability creation activities are organised as a separate SCCC project for each NPD project. Based on NPD process documentation, The NPD project and related project management team (PMT) is headed by the project manager. PMT team members are HW, SW, integration and verification ( $\& \mathrm{~V})$, finance and control $(\mathrm{F} \& \mathrm{C})$, marketing and sales $(\mathrm{M} \& \mathrm{~S})$, supply chain, service and care capability managers (Figure 5).

According to SCCC process guidelines, SCCC project is managed by the supply chain capability manager (SCCM) reporting to the head of NPD project manager. SCCM prepares the SCCC project plan and is responsible for SCCC process related activities in NPD project. SCCC team can consist of additional sub-managers such as purchasing capability manager (PuCM), production capability manager (PCM) and logistics capability manager (LCM) depending on the scope and size of the NPD and SCCC project. Not all sub-managers are necessary in every case. The smallest SCCC projects can be managed by the SCCM as one individual person but in the bigger NPD projects, the team of SCCC can consist of all four specific SCCC managers. The SCCC project members are typically resourced by the SC (Operations) organisation and its line organisations such as purchasing, production (manufacturing and testing) and logistics. In case of the sub-contracted production, the production capability manager can be nominated by the production partner. 


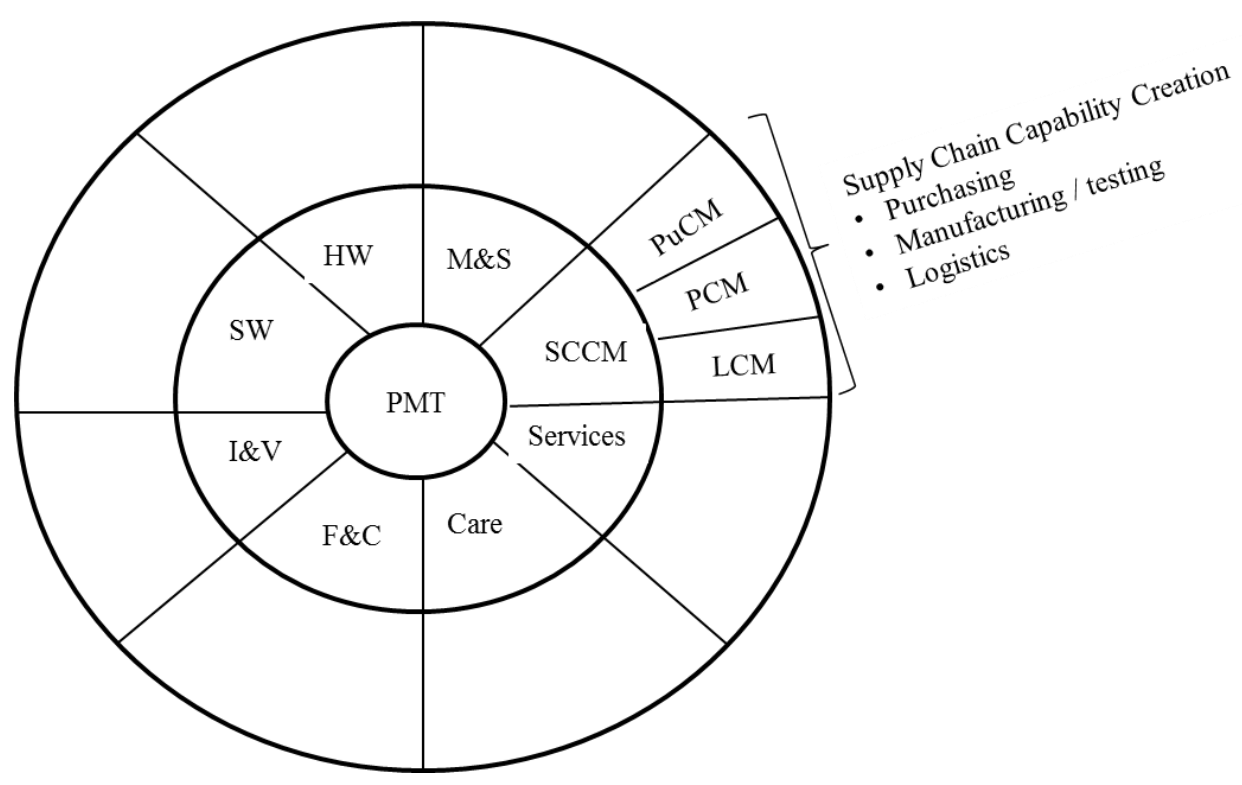

Figure 4. The structure of the NPD project management responsibilities.

\subsection{SCCC process implementation challenges in practice}

The semi-structured interviews with SCCC process owners and supply chain capability managers opened an interesting viewpoint to SCCC process implementation and usage in practice. Some clear challenges were identified. The SCCC process and it's few modifications are targeted as generic process guidelines for the major part of NPD projects. The more generic is the SC process, the more standard could be the assumed SCCC implementation. However, NPD projects differ as HW, SW and Services type of NPD projects. In addition, the scale of the NPD project can be different from technology and platform development projects to product variant and cost reduction related minor scale development projects.

The other interesting notification is the fragmented expectations about the SCCC process and its accuracy. The necessary details of the SCCC process as the number of activities and milestone criteria have been differently seen by the supply chain capability managers. While the other supply chain capability manager sees the SCCC process very applicable as the guideline, the other SCCM can see it too accurate. A couple of SCCMs said: "we have done much more accurate process guidelines for our real project work to secure the completeness of the supply chain capability". While some SW product development related SCCC projects can be done by one individual SCCM, the major new product development programs might need the separate SCCM and sub-SCCC project managers for purchasing, production and logistics capability creation activities.

Regardless of some criticism, the existence of the well-documented SCCC process and its utilisation within each NPD project were seen critical to ensure the efficient supply chain capability creation. Clear tasks and role definitions, accurate milestone review checklists and structured NPD project management teams were seen as the enablers for efficient work and high-qualified product ramp-ups. 


\subsection{The Preconditions for the systematic SCCC}

The systematic supply chain capability management can be built based on following preconditions:

\section{Mature supply chain process platforms.}

The existence of the described, implemented and managed supply chain process platforms by the nominated supply chain process owners and stakeholders including related efficiency requirements, targets and metrics

2. DfX product design concept as a part of SCCC process.

The existence of formally defined DfX concept including product design guidelines, targets and performance indicators according to the supply chain process platforms by the DfX concept owner and sub-disciplines.

\section{SCCC process as a sub-process of the NPD process}

The existence of the formally defined SCCC process including related governance models, roles, targets, performance indicators, tasks and milestone criteria by the SCCC process owner and sub-process owners.

4. Clear governance model for NPD and SCCC development and implementation

The existence of the formal governance model and resourcing for DfX and SCCC activities from the strategic target setting and alignment of NPD and supply chain processes to the operational SCCC execution in each NPD projects

The above preconditions can be seen as strategic elements in the companies and the availability of them cannot be seen self-evident. Even the availability of the precondition one, the strategic and implemented supply chain process platforms, might be missing and are not defined. The lack of the precondition one makes the rest of the preconditions inefficient. The development of the right type of product designs, such as products structures, configurability, modularity and testability call for the supply chain process platform descriptions. Even the creation of the supply chain capability itself would be inefficient without the targeted supply chain process platforms. Once the supply chain process models have been strategically defined and implemented the requirements for the DfX and SCCC activities as a part of NPD process can be set.

The overall target of the DfX and SCCC is to ensure smooth new product ramp-ups with minor product specific investments and SC process changes. This gives the flexibility for global operations to deliver different products at targeted supply chain process efficiency, the metrics being cost, time and quality. According to case company's experience, the cost efficiency, time-to-market and product quality can be improved by the systematic and well-documented DfX concept and SCCC process. The key SCCC issues are the use of well-qualified and documented existing SC processes.

- Purchasing capability creation: The use of a minimum total number of suppliers and purchased materials, which have been qualified and contracted. Any new unqualified supplier or purchased material will potentially add cost and time for the NPD project and lower the quality of the product or SC process.

- Production capability creation: The use of mature, qualified and well-documented production technologies, devices and processes. The development and evaluation of a new manufacturing and test technologies during the NPD process potentially increases the NPD time. However, using the new production technologies may reduce the operational production cost and product quality but increases the cost of individual product development projects.

- Logistics capability creation: The use of mature, qualified and well-documented inbound, inhouse and outbound logistics processes in order management, deliveries and invoicing will potentially decrease the NPD time and cost as well as increase the quality of the logistics 
processes. Any new logistics process development during the NPD process will add cost and time to individual NPD projects.

Naturally, the SC processes are developed to improve the overall efficiency such as cost, orderdelivery lead-time, on time delivery etc. However, the SC processes should not be tailored and developed within individual NPD projects but the SCCC should be executed based on the qualified and well-documented SC processes.

The SCCC project plan should outline all the relevant generic steps for a corporate size company to develop a new product and to be able to ship it out to the customers. SCCC plan can and should be adjusted to the company size and operating model. Many companies do not have production lines of their own, or they have possibly outsourced all supply chain activities. Even in these cases, all SCCC steps are needed to be carried out together with selected partners. SCCC is always a project, while the fact how big the project should be is largely dependent on the company size and the product characteristics. In this paper, the SCCC project is proposed to be a separate project under NPD project/program, following the same NPD milestone timelines but with its own SCCC process related tasks and milestone criteria. Only a product with well-established supply chain capability can be handed over to operations of mass production, purchasing and logistics. Supply chain capability management including DfX and SCCC is applicable and needed for HW, SW and service type of products.

\section{Discussion}

This study analyses the preconditions for a systematic supply chain capability creation process that is created during the NPD project. The analysed supply chain capability creation process consists of the activities that influence on the product design itself at early product specification as well as the concept phases and the activities to prepare the operational supply chain process (supply chain) for new product deliveries. The supply chain capability creation process consists of purchasing, production and logistics capabilities.

As a scientific implication, this study contributes to existing literature by introducing the supply chain capability creation process as a systematic sub-process of the NDP process and the related preconditions. The business processes as NPD (Cooper, 2001; Ulrich and Eppinger, 2008; Liker 2004) and SC (Su and Gargeya, 2012; Cheng et al., 2010) have been studied separately by the earlier research. The need for the better integration of the NPD and SC processes in the product development phase has been studied as well (Van Hoek and Chapman, 2007). The parts of the supply chain capability creation have been studied by the earlier research separately as purchasing capability creation (Berg 2007; Pufall et al., 2012; Almgren, 1999), production capability creation (Mukerji et al., 2010; Terwiesch and Bohn, 2001; Gross and Renner, 2010) and logistics capability creation (Pufall et al., 2007; Shang and Marlow, 2005). However, a holistic supply chain capability creation process should consist of the purchasing, production and logistics capability creation activities. In addition, the analysed SCCC process consists of design for excellence concept related activities, product design guidelines and targets to influence the product design itself in order to better fit the new product with the SC processes. According to the analysed empirical information, the supply chain capability management should be an integral part of the NPD process and related NPD project management team.

The managerial implication of this study includes the importance of the business process alignment and their systematic descriptions. The preconditions for the systematic supply chain capability creation activities involve the availability of well-described supply chain models and processes as a base for DfX product design guidelines and supply chain capability creation during the NPD phases 
to better reach the production economics within operational life-cycle phases. The aim of the DfX is to influence on product design in order to maximise the utilisation of generic supply chain models, suppliers, production investments. The product specific changes to supply chain process platforms should be avoided. The supply chain capability creation process is to be developed as a part of the NPD process. The SCCC process and the related sub-processes such as purchasing, production and logistics capability creation must be developed by the nominated SCCC process owner and the subprocess owners as an integral part of the NPD process development. The SCCC project must be established as a sub-project for each NPD project. The supply chain capability manager leads the SCCC project and reports to the NPD project manager who is a member of the NPD project management team. The SCCC project involves members from the operational SC functions to prepare the SC process for new products ramp-ups. The early involvement of competent SC resources to impact to product design and to prepare the SC ready for smooth product ramp up can been seen crucial from the overall production economics point of view over the life-cycle

\section{Conclusions}

NPD process aims for product portfolio renewal based on the efficient new product ramp-ups according to strategic and operational targets of the company. The NPD process should not manage pure product development activities only but also the supply chain capability creation activities. This requires the alignment and co-operation between NPD and SC processes. Supply chain capability is about the capability of delivering the product based on strategic and operational supply chain process platforms such as purchasing, production and logistics processes. Each of the sub-processes can enable, or endanger the supply chain capability, thus high integration is needed within the supply chain process and between other business processes.

The analysed case company has created and implemented a systematic supply chain capability creation process including the DfX product design concept over the last decades as a continuous type of process development approach. SCCC process has been integrated into their NPD process seamlessly as a sub-process. The related practices have been widely utilised in their NPD projects and programs globally. The preconditions for the systematic supply chain capability management are structured and described Supply Chain, NPD and SCCC processes by the nominated process owners and related governance models.

The analysed SCCC is a critical success factor for efficient product ramp-ups thus it is a potential area for further research and improvement academically and as a focus area for managerial attention within the industry. The supply chain capability management, as well as the related DfX concept and SCCC process, have not been studied widely on the academic side according to earlier literature. The strength of the paper is the analysis of the case company that has implemented SCCC as a sub-process of their NPD process including the DfX product design concept in practice because of systematic development of the topics within the last decades.

There are certain limitations in this study. The design for excellence (DfX) product design concept was left outside the analysis to keep the focus on SCCC. Indeed, the DfX product design concept (Lee, 1993; Kinnunen et al., 2014) enables the systematic and cost efficient use of existing SC processes for new products and related activities. The other limitation of the study is related to the empirical analysis of a single case company. Involving additional companies might provide some additional value, however, discussions with several potential other companies indicated a lack of organised and documented SCCC activities that would not provide further empirical knowledge for systematic SCCC process. Nevertheless, all the other potential companies identified the need for improvements in SCCC competence area. The research method followed the inductive approach and 
qualitative data analysis based on semi-structured interviews, also involving some methodology related limitations. DfX related product design targets and metrics could have provided the opportunity for quantitative data analysis between targeted and actual design metrics but was not is the scope of the study.

The further research in SCCC could involve more detailed analysis of the DfX product design concept and the SCCC process itself. In addition, the differences in supply chain capability creation related to HW, SW and Services products can be seen important both academically and for the industry. 


\section{References}

Adamines, E.D. and Pomonis, N., 2006. The co-evolution of product, production and supply chain decisions, and the emergence of manufacturing strategy, International Journal of Production Economics, 121 (2), 301-312.

Ahmed, P.K. and Rafiq, M., 2002. Internal marketing: Tools and concepts for customer-focused management. Routledge.

Almgren, H., 2000. Pilot production and manufacturing start-up: the case of Volvo S80. International Journal of Production Research, 38 (17), 4577-4588

Almgren, H., 1999. Towards a framework for analysing efficiency during start-up: An empirical investigation of a Swedish auto manufacturer. International Journal of Production Economics, 6061, 79-86.

Azzi, A., Battini, D., Persona, A. and Sgarbossa, F., 2012. Packaging design: general framework and research agenda. Packaging Technology and Science, 25 (8), 435-456.

Azzi, A., Battini, D., Persona, A. and Sgarbossa, F., 2010. Decreasing Network Complexity with Logistics Outsourcing: An Entropic Approach. International Journal Of Procurement Management, 3 (4), 339-360.

Bai, C. and Sarkis, J., 2013. A grey-based DEMATEL model for evaluating business process management critical success factors. International Journal of Production Economics, 146 (1), 281 292.

Ball, P.D., Roberts, S., Natalicchio, A. and Scorzafave C., 2011. Modelling production ramp-up of engineering products. Journal of Engineering Manufacture, 225 (6), 959-971.

Barczak, G., Griffin, A., Kahn, B., 2009. PERSPECTIVE: Trends and Drivers of Success in NPD, Practices: Results of the 2003 PDMA Best Practices Study, Product Innovation Management, 26 (1), 3-23.

Berg, M., 2007. Inadequacy of material supplies during production ramp-up, Swedish Production Symposium 2007. 1-8.

Carrillo, J.E. and Franza, R.M., 2006. Investing in product development and production capabilities: The crucial linkage between time-to-market and ramp-up time. European Journal of Operational Research, 171 (2), 536-556.

Chen, J., Reilly, R.R. and Lynn, G.S., 2005. The impacts of speed-to-market on new product success: the moderating effects of uncertainty. Engineering Management, IEEE Transactions on 52 (2), 199-212.

Cheng, Y., Madsen, E.S. and Liangsiri, J., 2010. Transferring knowledge in the relocation of manufacturing units. Strategic Outsourcing: An International Journal, 3 (1), 5-19.

Cooper, R.G., 2001. Winning at new products - Accelerating the process from idea to launch. 3rd ed., Perseus Publishing.

Cooper, R.G., Edgett, S.J., and Kleinschmidt, E.J., 2004. Benchmarking Best NPD Practices-II, Research-Technology Management, 47 (3), 50-59.

Elstner, S. and Krause, D., 2014. Methodical approach for consideration of ramp-up risks in the product development of complex products. Procedia CIRP, (20), 20-25.

Fawcett, S.E., Calantone, R. and Smith, S.R., 1997a. Delivery capability and firm performance in international operations. International Journal of Production Economics, 51 (3), 191-204.

Fawcett, S.E., Stanley, L.L. and Smith, S.R., 1997b. Developing a logistics capability to improve the performance of international operations. Journal of Business Logistics, 18 (2), 101-127.

Gerwin, D. and Barrowman, N.J., 2002. An evaluation of research on integrated product development. Management Science, 48 (7), 938-953. 
Groover, M. P., 2010. Fundamentals of modern manufacturing - Materials, Processes, and Systems. 4th ed., NJ, John Wiley \& Sons, Inc

Gross, U. and Renner, T., 2010. Coordination and Cooperation during Production Ramp-up: An Empirical Study of the European Manufacturing Industry. POMS 21st Annual Conference, Vancouver, Canada.

Haller, M., Peikert, A. and Thoma, J., 2003. Cycle time management during production ramp-up. Robotics and Computer Integrated Manufacturing, 19 (1-2), 183-188.

Hilletofth, P., Ericsson, D. and Lumsden, K., 2010. Coordinating new product development and supply chain management. International Journal of Value Chain Management, 4 (1-2), 170-192.

Hsu, C.C., Tan, K.C., Kannan, V.R. and Keong Leong, G., 2009. Supply chain management practices as a mediator of the relationship between operations capability and firm performance, International Journal of Production Research, 47 (3), 835-855.

Hüntelmann, J., Reinsch, S. and Märtens, A., 2007. Logistic- and Cost-Oriented Cross-Company Ramp-Up Planning. Digital Enterprise Technology, 115-122.

Khan, K.B., Barczak, G., Nicholas, J., Ledwith, A. and Perks, H., 2012. An Examination of New Product Development Best Practice, Journal of Product Innovation Management, 29 (2), 180-192.

Kontio, J. and Haapasalo, H., 2005. A project model in managing production ramp-up - a case study in wire harness industry. International Journal of Innovation and Technology Management. 2 (1), 101-117.

Kinnunen, T., Aapaoja, A. and Haapasalo, H., 2014. Analysing Internal Stakeholders' Salience in Product Development, Technology and Investment, 5, 106-115.

Kärkkäinen, H., Piippo, P. and Tuominen, M., 2001. Ten tools for customer-driven product development in industrial companies. International Journal of Production Economics, 69 (2), 161176.

Liao, S.H. and Kuo, F-I., 2014. The study of relationships between the collaboration for supply chain, supply chain capabilities and firm performance: A case of the Taiwan's TFT-LCD industry, International Journal of Production Economics, 151, 295-304.

Lee, H.L., 1993. Design for Supply Chain Management: Concepts and Examples. Perspectives in Operations Management: Essays in Honor of Elwood S. Buffa. R. K. Sarin. Boston, MA, Springer US, 45-65.

Li, H-H.J.K., Shi, Y.J., Gregory, M. and Tan, K.H., 2014. Rapid production ramp-up capability: a collaborative supply network perspective. International Journal of Production Research, 52 (10), 2999-3013.

Liker, J., 2004. Toyota Way, New York: McGraw-Hill, p.350.

Liu, X., Yun, S., Huang, X., Xing, J. and Xiong, Y., 2013. Study on logistics capability of manufacturing enterprise via AHP and fuzzy evaluation. Journal of Applied Sciences, 13 (24), 5729-5733.

Lynch, D.F., Keller, S.B. and Ozment, J., 2000. The effects of logistics capabilities and strategy and firm performance, Journal of business logistics, 21 (2), 47-68.

Lummus, R.R. and Vokurka, R.J., 1999. Defining supply chain management: a historical perspective and practical guidelines, Industrial Management \& Data Systems, 99 (1), 11-17.

Marsillac, E. and Roh, J.J., 2014. Connecting product design, process and supply chain decisions to strengthen global supply chain capabilities, International Journal of Production Economics, 147, 317-329.

Marshall, C. and Rossman, G.B., 1998. Designing Qualitative Research. 3rd edition, Thousand Oaks, Sage Publications, p.240.

McCutcheon, D. and Meredith, J.R., 1993. Conducting case study research in operations management. Journal of Operations Management, 11 (3), 239-256.

Miltenburg, J., 2005. Manufacturing strategy - How to formulate and implement a winning plan. 2nd ed., NY, Productivity Press. 
Morash, E.A., 2001. Supply chain strategies, capabilities, and performance, Tranporstation Journal, $41(1), 39-54$.

Mukerji, B., Fantazy, K., Kumar, U. and Kumar, V., 2010. The Impact of Various Dimensions of Manufacturing Capability on Commercialization Performance: Evidence from Canadian Manufacturing Sector. Global Journal of Flexible Systems Management, 11 (3), 1-10.

Patton, M.Q., 2002. Qualitative Research and Evaluation Methods. 3rd edition, Thousand Oaks, Sage Publications, 598.

Pekuri, A., Pekuri, L. and Haapasalo, H., 2013. The Role of Business Models in Construction Companies. Australasian Journal of Construction Economics and Building, 13 (3), 13-23.

Petersen, K.J., Handfield, R.B. and Ragatz, G.L, 2005. Supplier integration into new product development: coordinating product, process and supply chain design, Journal of Operations Management, 23 (3-4), 371-388.

Pinheiro de Lima, E., Gouvea da Costa, S.E., and Angelis, J.J., 2013. Performance Measurement Systems: A consensual analysis of their roles, International Journals of Production Economics, $146(2), 524-542$.

Pufall, A., Fransoo, J.C., de Jong, A. and de Kok, A.G. T., 2012. The Impact of Product Complexity on Ramp-Up Performance. Technische Universiteit Eindhoven, Netherlands.

Pufall, A., Fransoo, J. C. and de Kok, A. K.T., 2007. What determines product ramp-up performance? - A review of characteristics based on a case study at Nokia Mobile Phones, Technische Universiteit Eindhoven, Netherlands.

Sahlman, K. and Haapasalo, H., 2011. Objectives of strategic management of technology in a conceptual framework of enterprise practise, International Journal of Business Innovation and Research, 5 (2), 142-158.

Schmidt, J.B., Kumar R.S. and Mitzi M.M., 2009. Exploring New Product Development Project Review Practices*. Journal of Product Innovation Management, 26 (5), 520-535.

Schmitt, S. and Schmitt, R., 2013. Lifecycle oriented ramp-up - Conception of a quality-oriented process model. Proceedings of the 20th CIRP International Conference on Life Cycle Engineering, Singapore, 441-446.

Shang, K. \& Marlow, P. B., 2005. Logistics capability and performance in Taiwan's major manufacturing firms. Transportation Research, Part E 41, 217-234.

Siggelkow, N., 2007. Persuasion with case studies. Academy of Management Journal, 50 (1), 20-24.

Stauder J., Buchholz, S., Klocke F. and Mattfeld, P., 2014. A new framework to evaluate the process capability of production technologies during production ramp-up. Procedia CIRP, 20, 126-131.

$\mathrm{Su}$, J. and Gargeya, V. B., 2012. Strategic sourcing, sourcing capability and firm performance in the US textile and apparel industry. Strategic Outsourcing: An International Journal, 5 (2), 145-165

Suikki, R.M., Goman, A.M.J. and Haapasalo, H., 2006. A framework for creating business models a challenge in convergence of high clock speed industry, International Journal of Business Environment, 1 (2), 211-233.

Surbier, L., Alpan, G. and Blanco, E., 2014. A comparative study on production ramp-up: state-ofthe-art and new challenges. Production Planning \& Control, 25 (15), 1264-1286.

Swafford, P.M., Ghosh. S. and Murthy, N., 2006. The antecedents of supply chain agility of a firm: Scale development and model testing, Journal of Operations Management, 24 (2), 170-188.

Terwiesch, C., Bohn, R.E. and Chea, K.S., 2001. International product transfer and production rampup: a case study from the data storage industry. $R \& D$ Management, 31 (4), 435-451.

Tracey, M., Lin, J.S. and Vonderembse, M.A., 2005. The impact of supply-chain management capabilities in business performance, Supply Chain Management: An International Journal, 10 (3), 179-191.

Ulrich, K.T. and Eppinger, S. D., 2008. Product Design and Development, 4th ed., McGraw-Hill, New York, NY. 
Um, J., Lyons, A., Lam, H.K.S., Cheng, T.C.E. and Dominquez-Pery, C., 2017. Product variety management and supply chain performance: A capability perspective on their relationships and competitiveness implications, International Journal of Production Economics, 187, 15-26.

von Cube, J.P. and Schmitt, R., 2014. Execution of Ramp-Up Projects in Day-to-Day Operations through a Quantitative Risk Management Approach. Procedia CIRP, 20, $26-31$.

Van Hoek, R. and Chapman, P., 2007. How to move supply chain beyond cleaning up after new product development. Supply Chain Management: An International Journal, 12 (4), 239-244.

Ward, P.T., Bickford, D.J. and Leong, G.K., 1996. Configurations of Manufacturing Strategy, Business Strategy, Environment and Structure. Journal of Management, 22 (4), 597-626.

Yin, R.K., 2003. Case Study Research: Design and Methods. Sage Publications, Thousand Oaks

Yin, R.K., 2014. Case Study Research: Design and Methods. Sage Publications, Singapore. 


\section{Appendix 1: Topics in semi-structured interviews}

1. Supply chain process and its sub-processes

- What is the scope of supply chain process?

- What are the sub-processes (or sub-activities) of the supply chain process such as

- Demand planning, supply planning and demand/supply balancing?

- Supply management and purchasing?

- Production (manufacturing and testing)?

- Logistics (as order management, distribution and invoicing...)?

- Something else...?

2. New product development (NPD) process and its sub-processes

- What is a scope of the NPD process?

- What are the sub-processes (or sub-activities) of the NPD process such as

- HW design process,

- SW design process,

- Services design process,

- Marketing and sales capability creation process,

- Supply chain capability creation process and

- Service and care capability creation process?

- Something else...?

3. The structure and roles of the NPD project management team

- What is the structure of the NPD project management team such as

- HW sub-project leader/specialist,

- SW sub-project leader/specialist,

- Service sub-project leader/specialist,

- Marketing and sales capability leader/specialist,

- Supply chain capability leader/specialist and

- Service and care capability leader/specialist?

- Someone else...?

4. Supply chain capability creation

- Is the supply chain capability creation done in a proactive (during the NPD project) or reactive (after NPD project) way?

- How are the SCCC responsibilities and roles organised?

- What are the roles and their responsibilities?

- What is the structure of the SCCC process such as

- Demand/supply planning,

- Supply management and purchasing,

- Manufacturing and testing and

- Logistics.

- Something else...

- What are the main SCCC tasks in each NPD phase including SCCC sub-processes (areas)

- What are the targets and metrics to manage the performance of the SCCC sub-project and the process? 